\section{Diurnal Variation in Distal Femoral Cartilage Thickness}

\section{To the Editor:}

We read with great interest the article "Cartilage Thickness of the Knee Joint in Juvenile Idiopathic Arthritis: Comparative Assessment by Ultrasonography and Magnetic Resonance Imaging," by Pradsgaard, et $a l^{1}$. The authors investigated the distal femoral cartilage thickness by using magnetic resonance imaging (MRI) and ultrasonography (US) in children with juvenile idiopathic arthritis. They showed the correlation between sonographic and MR measurements of cartilage thickness and reported that the cartilage thickness in medial femoral condyle was lower than that in lateral femoral condyle. Measurement of distal femoral cartilage thickness using different imaging methods including US is a relatively new topic and there are a growing number of publications investigating cartilage thickness in healthy populations and different disease groups such as systemic sclerosis and systemic lupus erythematosus ${ }^{2,3}$. We comment here on diurnal variation of distal femoral cartilage thickness. So far, diurnal rhythm in cartilage thickness of femoral condyle has been highlighted in 4 MRI studies $^{4,5,6,7}$ and 1 US study ${ }^{8}$.

First, Waterton, et al demonstrated that cartilage thickness decreased up to $0.6 \mathrm{~mm}$ in knee joint during the day owing to biomechanical forces, although cartilage volume did not change in asymptomatic patients ${ }^{4}$. Sitoci, et al investigated the deformation and the thickness of tibial cartilage in the knee joint during loading exercises and variation between morning and evening in healthy young volunteers. The authors showed that knee cartilage thickness decreases during the day and recovers overnight by up to $8 \%$ with resting ${ }^{5}$. In another study, Coleman, et al showed that cartilage thickness of the right knee joint decreased from AM to PM in all areas except the patellofemoral groove and lateral femoral condyle, after an average of 8057 steps during daily activities ${ }^{6}$. Finally, Widmyer, et al examined the effect of body mass index (BMI) on diurnal variation of cartilage thickness in the knee joint ${ }^{7}$. Cartilage thickness on femoral condyles decreased significantly from AM to PM. BMI did not have an influence on diurnal cartilage strain in the femoral cartilage, but did in the tibial cartilage ${ }^{7}$. We investigated the diurnal variation in the thickness of distal femoral cartilage by using US in healthy adults and showed diurnal variations reaching up to $10.6 \% 8$. The mean decrease in the cartilage thickness varies between 0.19 and $0.21 \mathrm{~mm}$ in the condyles and 0.11 to 0.13 in the intercondylar area. Interobserver intraclass correlation coefficients varied between 0.602 to 0.869 (for measurements of cartilage thickness in different regions and for time of the examinations).

All these studies suggested that cartilage thickness has diurnal variation and decreases from morning to evening in the same day. Pradsgaard and colleagues explained that US and MRI examinations were performed in the same day; however, the exact time of the examination is also important for the measurements. Although the variations are small, diurnal rhythm may influence the results if the measurements were not performed synchronously.

ERKAN KILIC, MD; GAMZE KILIC, MD; SALIH OZGOCMEN, MD, Professor; Division of Rheumatology, Department of Physical Medicine and Rehabilitation, Erciyes University, Faculty of Medicine, Kayseri, Turkey. Address correspondence to Dr. E. Kilic, Erciyes Üniversitesi Tıp Fakültesi, Gevher Nesibe Hastanesi, Fiziksel Tip ve Rehabilitasyon AD, Romatoloji BD, Kayseri, 38039, Turkey.E-mail: ekilic.md@hotmail.com

\section{REFERENCES}

1. Pradsgaard DO, Fiirgaard B, Spannow AH, Heuck C, Herlin T. Cartilage thickness of the knee joint in juvenile idiopathic arthritis: comparative assessment by ultrasonography and magnetic resonance imaging. J Rheumatol 2015;42:534-40.

2. Kaya A, Kara M, Tiftik T, Tezcan ME, Ozturk MA, Akinci A, et al. Ultrasonographic evaluation of the femoral cartilage thickness in patients with systemic lupus erythematosus. Rheumatol Int 2013;33:899-901.

3. Kilic G, Kilic E, Akgul O, Ozgocmen S. Decreased femoral cartilage thickness in patients with systemic sclerosis. Am J Med Sci 2014;347:382-6.

4. Waterton JC, Solloway S, Foster JE, Keen MC, Gandy S, Middleton $\mathrm{BJ}$, et al. Diurnal variation in the femoral articular cartilage of the knee in young adult humans. Magn Reson Med 2000;43:126-32.

5. Sitoci KH, Hudelmaier M, Eckstein F. Nocturnal changes in knee cartilage thickness in young healthy adults. Cells Tissues Organs 2012;196:189-94.

6. Coleman JL, Widmyer MR, Leddy HA, Utturkar GM, Spritzer CE, Moorman CT 3rd, et al. Diurnal variations in articular cartilage thickness and strain in the human knee. J Biomech 2013;46:541-7.

7. Widmyer MR, Utturkar GM, Leddy HA, Coleman JL, Spritzer CE, Moorman CT 3rd, et al. High body mass index is associated with increased diurnal strains in the articular cartilage of the knee. Arthritis Rheum 2013;65:2615-22.

8. Kilic G, Kilic E, Akgul O, Ozgocmen S. Ultrasonographic assessment of diurnal variation in the femoral condylar cartilage thickness in healthy young adults. Am J Phys Med Rehabil 2015;94:297-303.

J Rheumatol 2015;42:11; doi:10.3899/jrheum.150418 